\title{
Gredos San Diego Cooperativa. Cooperar para emprender
}

\author{
Carlos de la Higuera
}

Sumario: Introducción. I. El camino de Gredos San Diego Cooperativa: 1.1. Planteamientos institucionales de Gredos San Diego. 1.2. Apuesta por la economía social. 1.3. Los Centros Gredos San Diego. 1.4. Mirando al futuro. II. ¿Cómo hemos llegado hasta aquí?: 2.1. 1984-1994 (primera etapa): subsistencia. 2.2. 1994-2000 (segunda etapa): asegurar el futuro. 2.3. 2000-2005 (tercera etapa): crecimiento. 2.4. 2005-2011 (cuarta etapa): plan estratégico. III. A modo de resumen.

Resumen: Este artículo analiza la experiencia cooperativa a través del modelo de Gredos San Diego, sus planteamientos institucionales y su historia desde el punto de vista de la gestión, incidiendo en las variables que posibilitan el éxito de una institución de propiedad colectiva. En primer lugar el autor hace un breve análisis de los principios que guían a la cooperativa, sus orígenes y su situación actual, incluyendo el desarrollo del Grupo Cooperativo GSD. Continúa explorando la evolución de la gestión, dividiéndola en cuatro etapas diferenciadas, para finalizar con un resumen que a modo de conclusiones escribió el anterior presidente de la cooperativa.

Palabras clave: cooperativa, gestión, management, propiedad colectiva, educación.

Abstract: This paper analyzes the cooperative experience through Gredos San Diego model, its institutional approaches and its history from the point of view of management, focusing on the variables that enable the success of a collective ownership institution. First, the author makes a brief analysis of the principles that guide the cooperative, its origins and its current situation, including the development of GSD Cooperative Group. It continues exploring the evolution of management, dividing it into four distinct stages, and concludes with a summary with the findings of the previous president of the cooperative.

Key words: cooperatives, management, collective ownership, education. 


\section{Introducción}

El mundo no se nos ha dado para contemplarlo, sino para transformarlo.

\section{J.M. Arizmendiarrieta}

Siempre que emprendes un proyecto se procuras imaginar cual será su desarrollo, con qué medios contarás y quienes serán tus compañeros. Sueñas con un final dichoso con arreglo a unos principios y valores que te movieron a dar el primer paso. No hay dos proyectos iguales, la localización de los mismos, la cultura, las normas sociales, los principios religiosos, la temporalidad, etc. los hacen diferentes.

Si hay paralelismo, sin embargo, entre las fuentes de inspiración que invitan a dar el primer paso y que te acompañan a lo largo del camino. Los pioneros que llegaron a la costa oriental de lo que habrían de ser los actuales Estados Unidos buscaban un nuevo mundo, no solamente geográfico, en el que pudieran aplicar las nuevas ideas de la Ilustración que, nacidas en Francia, se habían extendido por otras zonas de Europa.

Son esas ideas las que quedan reflejadas en los primeros textos que habrían de conducir hacia la Constitución escrita más vieja en el país democrático más joven, dando lugar a otra forma de gobierno. Probada su eficacia en la práctica, serían fuente de motivación en un viaje de ida y vuelta, al ser aplicadas en la Revolución Francesa de 1789.

De igual manera, Gredos San Diego desde sus orígenes tuvo clara la necesidad de tener un modelo de referencia en el que inspirarse, unas ideas que pudieran aplicarse en otras latitudes, culturas, etc. y lo halló en las ideas del fundador de la experiencia de Mondragón, con la ventaja de que la praxis ya existía, circunstancia que no se dio en los primitivos pobladores de los Estados Unidos, que huían de la intolerancia.

El pensamiento «El mundo no se nos ha dado para contemplarlo, sino para transformarlo» nos mueve a la tarea desde una base laica, no laicista, no excluyente, desde un impulso motivado hacia el trabajo que ha marcado nuestro camino hasta el día de hoy.

\section{El camino de Gredos San Diego Cooperativa}

Gredos San Diego es una cooperativa de trabajadores de la enseñanza en la que tanto los profesores como el personal de administración y servicios son socios cooperativistas. Cumplidos los 25 años de 
existencia en abril de 2010, fue distinguida el 2 de mayo del mismo año, con la Medalla de Plata de la Comunidad de Madrid por «trabajar en el desarrollo de los sistemas educativos y la creación de empleo».

Gredos San Diego Sociedad Cooperativa Madrileña es una empresa de enseñanza de trabajo asociado, integrada en la Economía Social, que presta un servicio de interés público desde la óptica de la eficacia de la empresa privada. La plantilla de Gredos San Diego Cooperativa está compuesta actualmente por más de 1.300 trabajadores entre personal docente y no docente, de los cuales casi 900 son socios. Estos datos la sitúan como la primera Cooperativa de Enseñanza de España, con un $5 \%$ de cuota de mercado en esta comunidad, lo que ha hecho posible la creación y desarrollo del primer Grupo Cooperativo de la Comunidad de Madrid y uno de los pocos existentes en nuestro país.

Los Colegios Gredos San Diego son laicos y su ideario fomenta la tolerancia y libertad de ideas, inculcando valores educativos basados en el respeto a la dignidad humana, promoviendo el interés por el descubrimiento y el estudio tanto en el campo científico como humanístico.

En la actualidad, Gredos San Diego Cooperativa gestiona seis colegios en la Comunidad de Madrid: Colegio Gredos San Diego Vallecas (inaugurado en 1994), Colegio Gredos San Diego Moratalaz (septiembre 2000), y Colegio Gredos San Diego El Escorial (septiembre 2003); con el comienzo del curso 2007/08 abrieron sus puertas Las Suertes, en el Ensanche de Vallecas, y Las Rozas; en septiembre de 2008 entro en funcionamiento GSD Guadarrama.

Así mismo, el Colegio Gredos San Diego Alcalá, se pone en marcha desde el curso 2007/08 en Alcalá de Henares mediante un acuerdo de colaboración con la cooperativa Educación Activa Complutense, para la edificación y puesta en marcha de un centro educativo con el mismo modelo de gestión de GSD.

Ya en 2012, se integra en la Cooperativa el Centro de Estudios Santa María del Castillo, que a partir del curso 2012-2013 es Gredos San Diego Buitrago, situado en Buitrago de Lozoya, en la Sierra Norte de Madrid, propiedad hasta ahora de la Obra Social Caja Madrid.

El Centro cuenta actualmente con 944 alumnos de Educación Secundaria, Bachillerato, y una amplia oferta de Ciclos Formativos de Grado Medio y Superior, además de Programas de Cualificación Profesional Inicial y Formación Ocupacional. En sus instalaciones podemos encontrar extensas zonas verdes, instalaciones deportivas con canchas, pistas de deporte y piscina con dimensiones olímpicas; una residencia para los estudiantes; biblioteca y talleres para el desarrollo de la Formación Profesional. 
De esta forma Gredos San Diego refuerza su apuesta por una Formación Profesional de calidad y abre el camino a nuevos proyectos entre los que se encuentran centros de alto rendimiento en arte y deporte, así como un centro universitario, dando también servicio a las empresas para contribuir económica y empresarialmente al proyecto, creando un Centro de Educación Superior que una el mundo de la educación con el mundo laboral.

Gredos San Diego aprovechará de esta forma el capital humano y el potencial que posee a través de sus veintisiete años de experiencia acumulada en la acción educativa de jóvenes entre cero y dieciocho años, con un nuevo proyecto de iniciativa social que ejerza una acción directa positiva en su entorno.

\subsection{Planteamientos institucionales de Gredos San Diego}

Gredos San Diego, desde sus orígenes, ha tenido como guía de actuación los Principios Cooperativos, siguiendo el criterio de que esta guía solidaria de actuación, basada en las personas como centro de la actividad económica, no es solamente un conjunto de normas relativas a la ética empresarial, sino una verdadera fuente de ventajas competitivas para las cooperativas.

La Misión de Gredos San Diego es «atender a las personas para su desarrollo y formación en diferentes etapas de la vida, con el fin de mejorar la sociedad. Nos diferencian desde nuestros inicios, el desarrollo de proyectos educativos y la creación de empleo desde un modelo de economía social».

Su objeto social es «mantener, mejorar y seguir creando, ante todo para sus socios, puestos de trabajo en régimen cooperativo en centros docentes propios, habilitados para impartir enseñanza desde la etapa infantil hasta el nivel de secundaria, la enseñanza no reglada y la ocupacional y otros tipos de acciones formativas, medias o superiores, que puedan ofrecerse conforme a la legislación vigente. Para ello procurará estimular la vocación, capacitación y rendimiento de sus cuadros humanos, así como optimizar la rentabilidad de los medios materiales, que estarán siempre al servicio preferente de los socios, alumnado y comunidad del entorno. En todo caso, entrará en el objeto social, la formación deportiva, así como las actividades culturales, la investigación y las publicaciones relacionadas con las acciones desarrolladas por los socios en esta Cooperativa».

En este sentido, y como principal característica de GSD, es destacable, incluso por la relevancia en su misión y objeto social, que el princi- 
pal objetivo de la Cooperativa, es la creación de empleo. La trayectoria de estos años ha demostrado que la inversión siempre ha estado orientada en esta línea, como demuestran los siguientes gráficos, que comparan la evolución del número de socios, pasando de los 18 iniciales a 850 en la actualidad, tanto con la facturación, incrementada notablemente con la apertura de nuevos centros, como con el descenso puntual de los excedentes empresariales, en los momentos en que se ha incrementado el endeudamiento con la intención de crecer.

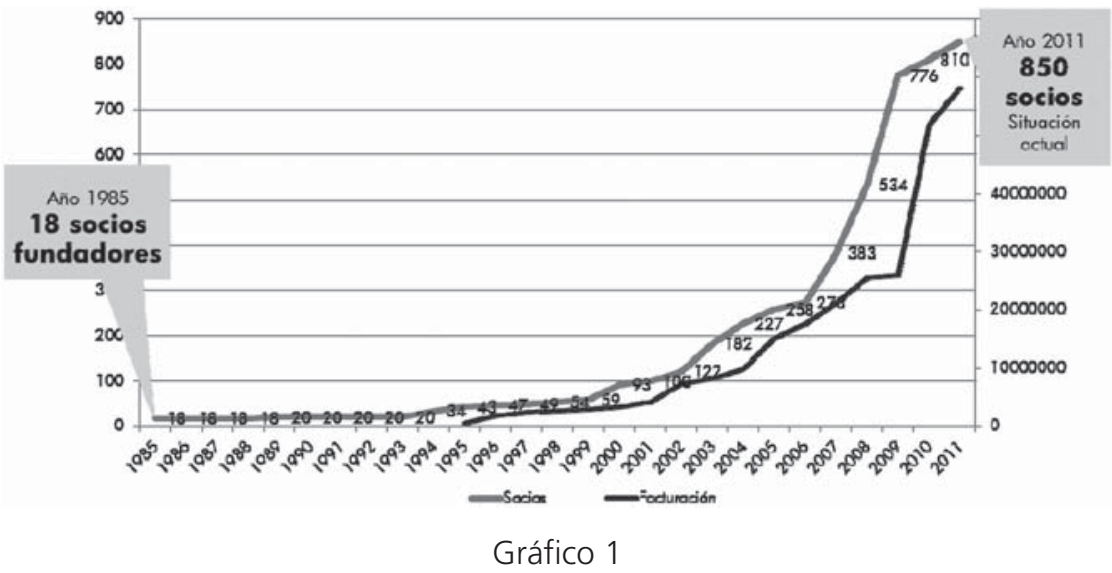

Número de socios vs. facturación

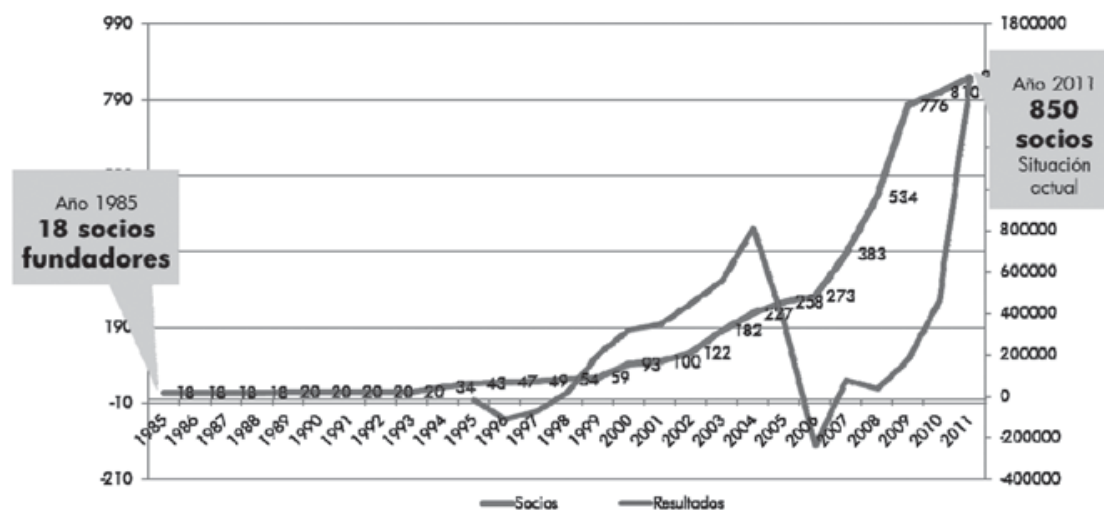

Gráfico 2

Número de socios vs. excedentes 
Especialmente este último gráfico nos aporta una segunda lectura, la apuesta por el crecimiento, por el empleo de calidad y en definitiva por las personas, ha dado como resultado una fortaleza económica que pone a la Cooperativa en el camino para afrontar con éxito nuevos retos.

\subsection{Apuesta por la economía social}

A lo largo de estos 27 años, Gredos San Diego S. Coop. Mad., ha cumplido los objetivos con los que se creó, pero ya ha emprendido otros nuevos como ha sido la creación del Grupo Cooperativo GSD para generar y apoyar iniciativas en el marco de la Economía Social. De hecho la «Visión» de Gredos San Diego, su apuesta de futuro, está orientada principalmente a su desarrollo:

«Consolidar el Grupo Cooperativo GSD promoviendo su crecimiento y siendo reconocidos a nivel nacional e internacional por nuestro dinamismo, servicios de calidad, capacidad de innovación y de mejora continua, así como la creación de puestos de trabajo.»

En agosto de 2006 abrió sus puertas en Leganés la Residencia de Mayores Los Balcones, gestionada por la cooperativa Tosande, integrada en el Grupo GSD, y a la que Gredos San Diego Cooperativa presta asesoramiento técnico para la administración del centro y apoyo financiero, además de haber supervisado las obras de construcción.

Un año después se creó la Cooperativa El Mercante, cuyo principal objetivo es el diseño, creación y distribución de producción textil. La primera actividad para Gredos San Diego fue el diseño de las camisetas con el lema « $\mathrm{H}_{2} \mathrm{O}$ te da vida», que se vendieron a beneficio de ACNUR, y han creado los uniformes de los Colegios GSD que utilizan los alumnos desde el curso 2007-2008 y la ropa laboral. Asimismo, ha creado los uniformes para varios centros escolares de toda España.

Igualmente, forma parte del Grupo Cooperativo GSD, la cooperativa Educación Activa Complutense, que gestiona el Colegio Gredos San Diego Alcalá. La última incorporación al grupo ha sido la creación de la cooperativa Artemus S. Coop. Mad., dedicada a la enseñanza artística de la música y la danza.

La cabeza del Grupo Cooperativo GSD es Gredos San Diego Cooperativa, que ha sido reconocida por CEPES, en su informe de Empresas relevantes de la Economía Social 2009/2010, como la primera cooperativa de enseñanza de España, en cuanto al número de socios- 
trabajadores y la primera institución educativa no universitaria de la Comunidad de Madrid en cuanto al número de alumnos que cobijan sus aulas, así como la $14 .^{a}$ empresa por número de empleados de Economía Social en toda España.

El Grupo Cooperativo GSD factura 75 millones de euros; ha creado 1.500 empleos estables y de calidad, de los cuales alrededor de 1.000 son socios cooperativistas. Como muestra de la actividad desarrollada, se dan cada día 10.000 comidas, lo que pocas empresas de hostelería pueden alcanzar; y sumando todos sus centros escolares, atiende a 12.000 alumnos.

Como muestra del apoyo a la diversidad, casi el $72 \%$ de la empresa está formada por mujeres, que ocupan prácticamente el $53 \%$ de los puestos directivos, de las cuales, es importante señalar que el 46,8\% tiene hijos mejores de 12 años. Los trabajadores del Grupo GSD proceden de 22 países distintos.

La estructura democrática de Gredos San Diego, regida por los principios cooperativos, sin menoscabo de la búsqueda permanente de la eficiencia empresarial, facilita que los conceptos de empresa socialmente responsable y de cooperación, se asuman como parte de la gestión, ya que forman parte del ADN de la empresa.

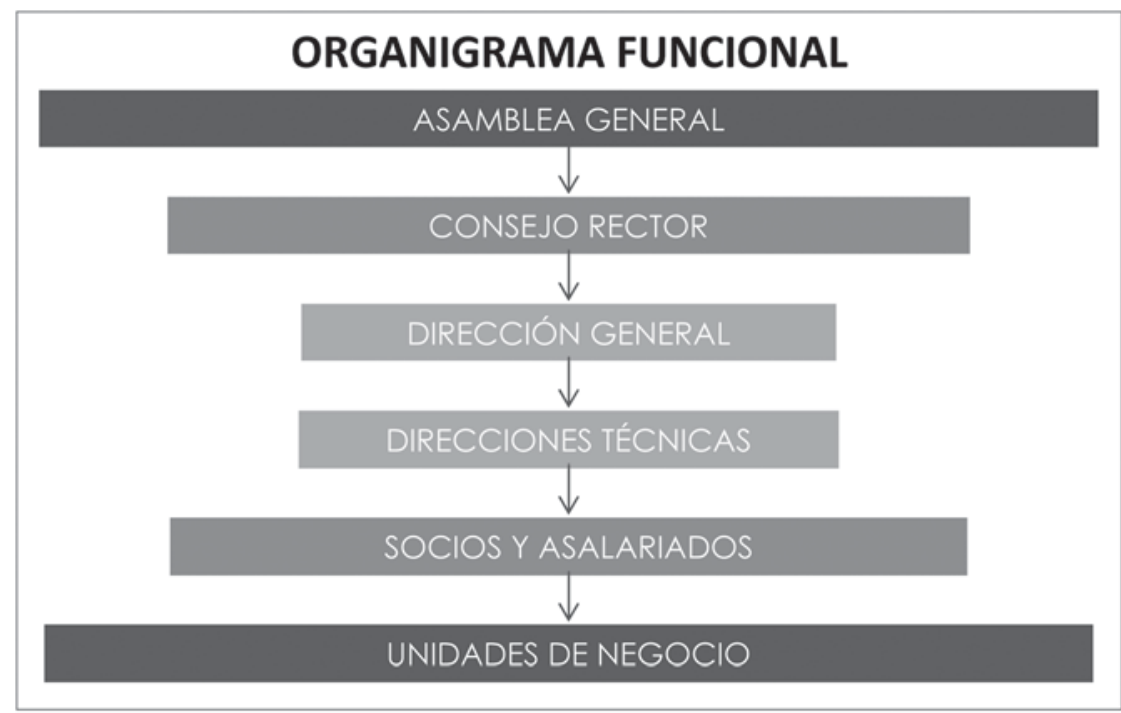

Gráfico 3

Organigrama de Gredos San Diego Cooperativa 


\subsection{Los Centros Gredos San Diego}

La Cooperativa Gredos San Diego está compuesta en la actualidad por ocho centros escolares, seis de los cuales son colegios que siguen un modelo integral de educación, ya que acogen a alumnos de cero a dieciocho años, incluyendo en la actualidad tanto Educación Secundaria y Bachillerato como Formación Profesional; a estos colegios, se suman dos Centros en la Naturaleza.

- Gredos San Diego Vallecas: Es el centro más grande en número de alumnos y trabajadores del Grupo Cooperativo. Se crea en 1994 con seiscientos alumnos llegando hoy en día a sobrepasar los dos mil después de la ampliación y anexión del cercano edificio el antiguo colegio de Ursulinas convertido en amplio espacio para la educación infantil.

- Gredos San Diego Moratalaz: En el año 2000 se crea y comienza a funcionar como resultado de la fusión por absorción de Sapientia, S. Cooperativa. Está situado en una zona con claro déficit y alta demanda de puestos escolares por la remodelación de la zona y la ampliación del barrio de Valedebernardo. El centro cuenta actualmente con unos 1.800 alumnos desde 0 a 18 años, infantil, Primaria, Secundaria y Bachillerato.

- Gredos San Diego El Escorial: Abre sus puertas a la actividad educativa en el 2003 en la zona de influencia de El Escorial y Galapagar a orillas del embalse de Valmayor respondiendo a la vocación ecológica de la Cooperativa desde sus orígenes, como muestra de ello fue pionero en el proyecto de Ecoescuelas entre los Centros GSD, y el primero de ellos en obtener el galardón «Bandera verde» otorgado por ADEAC. Actualmente cuenta con alrededor de 1.500 alumnos desde Infantil a Bachillerato.

- Gredos San Diego Las Suertes: Comienza su andadura en el 2007 y en la actualidad dispone de una oferta completa en educación no universitaria incluyendo Educación Infantil, Primaria, Secundaria, Bachillerato, y Formación Profesional compuesta tanto de módulos de Grado superior (Animador de Actividades Físicas y Deportivas, Administración y Finanzas, Educación Infantil) como de Grado Medio (Gestión Administrativa). En total el centro atiende a 1.700 alumnos aproximadamente.

- Gredos San Diego Las Rozas: Abrió sus puertas en 2007 y en estos momentos cuenta con una matrícula que supera los 1.800 alumnos, desde Educación Infantil a Bachillerato, habiendo alcanzado en solo dos años el 99\% de su ocupación 
máxima. Con la intención de crear el primer centro universitario del grupo cooperativo fue proyectado y construido un pabellón que responde al estilo y exigencias funcionales de los estudios de grado de Educación Infantil.

- Gredos San Diego Guadarrama: Inicia su andadura en 2008 para dar respuesta educativa a las necesidades de escolarización de la zona de la Sierra Oeste. Con 1.300 alumnos escolarizados en este momento, tiene capacidad para crecer en la oferta de formación profesional hasta llegar a ofertar 1.600 plazas.

- Aula en la Naturaleza La Vía Láctea: Se crea y pone en funcionamiento en 2003, junto a las instalaciones de El Corralón, alojamiento rural en Casavieja (Ávila), cuya actividad también se mantiene. Dispone de un completo programa de educación infantil y juvenil de 5 a 12 años que comprende sendas e itinerarios para conocer la naturaleza, talleres (huerto, velas, etc.), juegos, cuaderno de campo, astronomía y campamentos de verano, impartido por un equipo profesional estable de educadores especializados en la naturaleza. Sus instalaciones comprenden siete cabañas, dormitorios, comedor, aula de formación con medios audiovisuales e informáticos, piscina, zona de juegos infantiles y telescopio con control digital.

- Aula en la Naturaleza Sendas del Riaza: Ubicada en Valdevacas de Montejo (Segovia), localidad que cuenta con 30 habitantes, en la que gracias a la apertura de este Centro se han creado nueve puestos de trabajo estables, lo que favorecerá, además de la permanencia de personas del entorno, la oportunidad de que nuevos habitantes puedan instalarse en el propio municipio o en sus proximidades. La gestión ha sido cedida a Gredos San Diego por la Fundación Patrimonio Natural, y además de su función pedagógica se mantiene disponible al público en general como albergue.

Cuenta con un espectacular entorno natural, en el que destacan el Parque Natural del Río Riaza y el Espacio Natural del Enebral de Hornuez. Dispone de alojamiento para 75 personas, en habitaciones dobles o grupales, comedor y salas de reuniones y de estar.

Para educar a los alumnos en el respeto del medio, se ha puesto en marcha un innovador proyecto educativo dirigido a alumnos de Secundaria, que tiene como espacio la naturaleza y como hilo conductor la aplicación de las tecnologías de la comunicación, centrado en fotografía digital, vídeo, orientación con GPS y fotografía del cielo nocturno a través de telescopio. 
- Otras actividades: Además de la educación reglada en sus Centros Escolares, Gredos San Diego diversifica su actividad en otras áreas educativas, como la Formación para el Empleo, una Escuela de Música, una muy activa Área de Intercambios con otros países, además de aprovechar su experiencia en la gestión cooperativa para facilitar asesoramiento a otras empresas.

\subsection{Mirando al futuro}

Gredos San Diego, nació desde sus orígenes con una vocación de emprendimiento, que una vez superada la etapa de supervivencia, lleva a la cooperativa a emprender desde el principio proyectos ambiciosos. Este espíritu empresarial, que para Gredos San Diego toma el sentido más amplio de la palabra: como proyecto de futuro que nace y se desarrolla con el afán de perdurar en el tiempo, de aportar dinamismo y riqueza a la sociedad, y de promover el desarrollo de las personas, en el momento actual está haciendo suya la idea de «pensar en global y actuar en local», que se plasma en dos caminos.

Por una parte el desarrollo del Grupo Cooperativo GSD, que siempre toma como referencia el Principio Cooperativo de Intercooperación. Las cooperativas compiten como cualquier empresa en un mercado global, bajo los principios de la economía de mercado, pero la cooperación entre ellas, facilita que adquieran un mayor peso específico que aporta grandes beneficios económicos, desde una mayor capacidad de negociación, a la potencialidad que otorgan las economías de escala, en cuanto a la posibilidad incluso de desarrollar productos o servicios cuyos costes no podrían ser asumidos por cada una de las empresas de forma independiente.

El otro extremo de este enfoque pone de relevancia el desarrollo local, valorando esta postura desde un criterio empresarial basado en el desarrollo sostenible y en una verdadera convicción del potencialidad de las zonas rurales, no solo como entorno turístico, también formativo, ecológico y empresarial. Los últimos proyectos de Sendas del Riaza y GSD Buitrago se encuentran en esta línea.

Especialmente GSD Buitrago se configura como proyecto como un ambicioso Centro de Educación Superior, con la intención de desarrollar un verdadero cluster de conocimiento en la zona que favorezca la implantación de empresas, el fomento de la vocación emprendedora y de investigación de los alumnos, y el acercamiento del mundo corporativo a la educación, que tradicionalmente ha estado en nuestro país de espaldas a éste. Gredos San Diego quiere crear un verdadero centro 
de conocimiento, innovación, y formación, con una absoluta vocación transformadora de la sociedad, en la Sierra Norte de Madrid, una de las zonas menos desarrolladas de esta Comunidad.

En un entorno competitivo como el actual, marcado por la crisis económica e incluso institucional, desde Gredos San Diego se apuesta por la innovación, la calidad y la flexibilidad que aporta la implicación de los trabajadores en el capital de las empresas. La idea que sostiene el Grupo Cooperativo GSD es que la unión de las personas trabajando en equipo da como fruto un talento mayor que el de esas personas por separado.

\section{II. ¿Cómo hemos llegado hasta aquí?}

El camino para llegar a este punto, situarse como la primera institución de enseñanza no universitaria de la Comunidad de Madrid, y la creación de uno de los pocos Grupos Cooperativos que existen en nuestro país, no ha sido fácil ni casual.

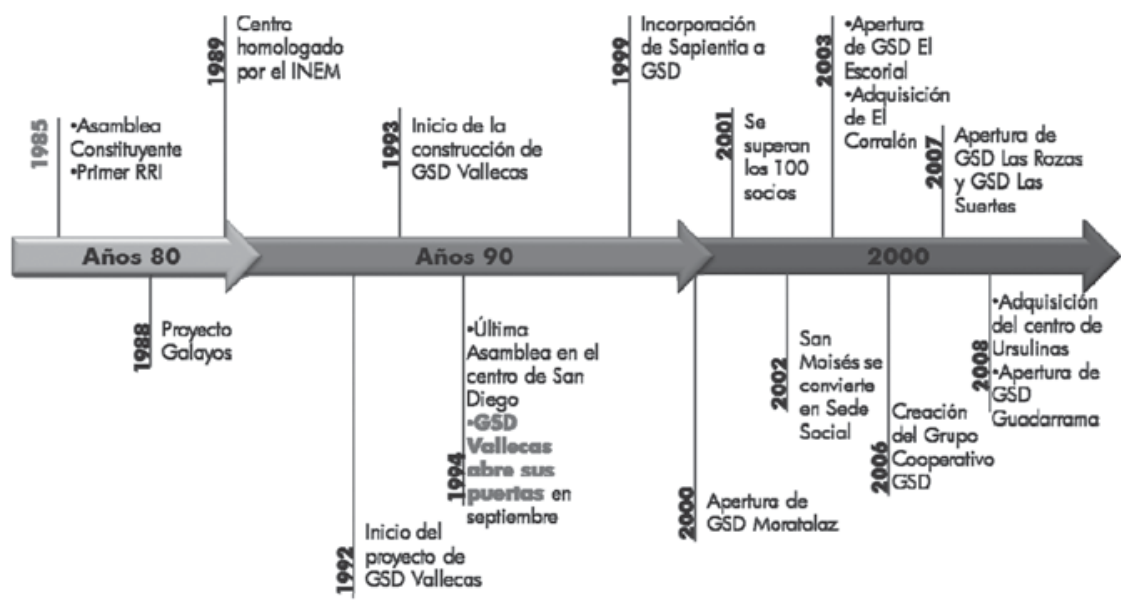

Gráfico 4

\section{Principales hitos en la historia de Gredos San Diego}

\subsection{4-1994 (primera etapa): subsistencia}

Gredos San Diego nace de la rebeldía, de un impulso de resistencia de sus trabajadores que ven en peligro sus puestos de trabajo y deci- 
den plantar cara a esta situación. Lo que hace especial esta decisión es que toman la determinación de hacerlo por sus propios medios y salvar sus empleos ellos mismos.

La primera etapa de Gredos San Diego, desde 1984 en que comenzaron los preparativos para la constitución de la Cooperativa, está marcada por la necesidad de supervivencia. En este momento no está desarrollada aun la idea de empresa, los trabajadores de Gredos San Diego únicamente piensan en la subsistencia del Colegio y el mantenimiento tanto de sus puestos de trabajo como de las plazas escolares de sus alumnos.

Estos primeros años se caracterizan por la organización informal que define a las pequeñas empresas, todo el mundo desarrolla todas las tareas. El fuerte liderazgo del Presidente, que con un grupo de colaboradores consigue salvar los escollos del día a día, mediante el refuerzo de las relaciones interpersonales y buscando siempre convencer más que vencer, posibilita tomar las decisiones correctas de cara a ir superando poco a poco el asamblearismo inicial, que dificulta considerablemente la gestión.

Este es uno de los principales escollos con los que deben enfrentarse las cooperativas, sobre todo en sus momentos iniciales. Para que la toma de decisiones fluida y guiada por criterios empresariales y de gestión, se imponga sobre el lento proceso de votar cada una de las decisiones, lo que deja a algunas cooperativas en una situación que no les permite competir en un mercado cada vez más dinámico, es necesario que la democracia adquiera una verdadera dimensión representativa, la Cooperativa se dote de una estructura formal que tome decisiones de negocio, y los socios distingan claramente su papel como tales en la asamblea de su trabajo diario.

En estos primeros pasos, si bien Gredos San Diego aun no ha conseguido dotarse de esa estructura, sí que comienza a orientarse hacia este modelo. Son años muy difíciles, de travesía en el desierto, nadie augura que el proyecto sea viable. Desde ámbitos externos a la Cooperativa, se plantea incluso que el descenso de la natalidad les dejará fuera del mercado educativo. Si algo caracteriza a las personas que estuvieron presentes desde esta primera etapa es la ilusión, el tesón, y la fuerza de voluntad para no dejarse vencer por las adversidades que tuvieron que sufrir en un entorno considerablemente complicado, y con una falta de recursos que les obligó a poner en práctica todas sus potencialidades personales y profesionales.

El primer colegio en Vallecas, que da origen a la empresa, había dejado de cumplir los requisitos legales para seguir en funcionamiento, y se imponía ya como necesidad la construcción de un nuevo Centro, para el que no parecía posible conseguir ni siquiera los terrenos. 
Este liderazgo positivo del presidente, va configurando un proyecto viable que pese al reparo de algunas instancias, finalmente consigue abrirse camino hasta concluir en 1994 con la apertura del nuevo Colegio de Vallecas dando paso a una nueva etapa para Gredos San Diego Cooperativa.

\subsection{4-2000 (segunda etapa): asegurar el futuro}

La apertura de GSD Vallecas supone la consolidación de Gredos San Diego como colegio, su fuerte presencia en el barrio hace realidad la implantación de nuevas líneas educativas, la inclusión desde un principio de educación secundaria, en ese momento BUP y COU, y da al Centro la posibilidad de desarrollar toda una serie de actividades que hasta el momento resultaban inviables dadas las instalaciones del antiguo colegio.

Como ejemplo de estas nuevas opciones que siempre habían estado en mente del equipo fundador, hacía años que los alumnos acudían a clases de natación a través de acuerdos con instalaciones deportivas municipales en el mismo horario escolar, pero la apertura del nuevo colegio con su propia piscina climatizada, hacía posible introducir la natación como parte del programa de la asignatura de educación física en todos los niveles. Del mismo modo, el comedor ya contaba con su propia cocina, y como todas las instalaciones de laboratorios, biblioteca, deporte, etc. daban al centro unas posibilidades que antes resultaban utópicas.

De esta forma nace el modelo de Gredos San Diego, un centro integrado de 0 a 18 años, en el que la vocación de servicio a las familias posibilita que dentro del ámbito de la enseñanza concertada se ofrezcan todas las facilidades de un colegio privado. Sirva como ejemplo de este proyecto el convencimiento del Centro de que la enseñanza debería orientarse al bilingüismo antes siquiera de que este modelo estuviera contemplado legalmente en la enseñanza concertada.

Mediante la integración paulatina del inglés tanto como asignatura, como su utilización como lengua vehicular en otras materias, se fue consiguiendo la conversión del Colegio en un centro bilingüe, de tal forma que sirvió como modelo en el proceso de implantación del bilingüismo para los colegios públicos de la Comunidad de Madrid.

El crecimiento de la empresa tanto en volumen de negocio como en número de trabajadores, alcanzando en 2001 los 100 socios, afianza el proyecto, y el desarrollo de una estructura más solida atenúa el asamblearismo. Asimismo la entrada de estos nuevos socios que 
vienen a reforzar el proyecto tanto dándole un nuevo impulso y ratificando el liderazgo; da lugar a una nueva visión de la Cooperativa, ya no solo como colegio, también como empresa con un pensamiento estratégico que empieza a perfilar el futuro.

En los últimos años 90, Gredos San Diego comienza a asesorar de manera informal a la Cooperativa Sapientia, que tenía como proyecto la apertura de un Colegio en Moratalaz, aprovechando el crecimiento del barrio mediante el proyecto de lo que sería Valdebernardo.

Tras una serie de contratiempos, Sapientia se ve abocada a una situación de crisis de difícil solución, sobre todo debido a problemas con la financiación del futuro centro escolar. Gredos San Diego sale al paso, la relación con los compañeros de Sapientia se había ido estrechando durante el tiempo de colaboración, y crea una obligación moral de no dejarles caer, debido posiblemente a que se vieron reflejados en su situación por las vivencias de que ellos mismos provenían.

Tras barajar distintas alternativas se propone a Sapientia una fusión por absorción por parte de Gredos San Diego. Los socios de Sapientia se integran como miembros de pleno derecho en Gredos San Diego y el colegio se convierte finalmente en Gredos San Diego Moratalaz, que abre sus puertas en el año 2000, iniciando la expansión de la empresa más allá de su primera concepción como Colegio.

\subsection{0-2005 (ttercera etapa): crecimiento}

El paso de ser un único Colegio a dos Centros supone un reto en la organización que tiene una doble vertiente. Por un lado representa un fortalecimiento de su estructura de, que a partir de ese momento incluye entre sus objetivos el mantenimiento de un modelo único tanto educativo como de calidad y servicios, que pese a las divergencias que puedan surgir por las peculiaridades de cada centro, se convierte desde el principio en una nueva visión.

Desde ese momento la Cooperativa empieza a ocuparse de un nuevo concepto, la marca, y es necesario implantar estándares de actuación entre ambos centros que posibiliten una verdadera ventaja competitiva. Este hecho, que en este momento se impone como una necesidad de coherencia, será vital en el futuro de cara a la apertura de nuevos centros.

Por otra parte, se produce al mismo tiempo una resistencia al cambio, que se expresa principalmente en un rechazo subyacente al crecimiento, principalmente por un afán conservador. De nuevo se hace 
patente el liderazgo y poco a poco va calando la idea de que el crecimiento de la empresa, más que una posibilidad es una necesidad, que una mayor fortaleza dará a la Cooperativa la independencia y peso específico suficiente para afrontar el porvenir con solvencia.

Aparece de esta forma una visión estratégica del negocio, ya no como presente sino como posibilidad real de futuro. Esta nueva mentalidad se hace patente en la apertura del aula en la naturaleza La Vía Láctea. Desde sus orígenes el colegio había dado especial importancia al contacto de los alumnos con el medio natural, en principio a través de precarios campamentos que constituían una verdadera aventura organizativa.

El desarrollo de esta idea lleva al colegio a desarrollar un nuevo proyecto de basado en la adquisición de un centro propio, que no sólo haga crecer a la empresa, sino que convierta el modelo educativo de los colegios en pionero en la implantación de una verdadera educación ambiental que conecte los contenidos del aula con el aprendizaje en el entorno natural.

Además de este nuevo entorno de trabajo, se construye un nuevo Centro: Gredos San Diego El Escorial, que supone tanto la consolidación del crecimiento, como el inicio de una andadura lejos del origen de la empresa, en la Sierra de Madrid. Es en este momento cuando se hace más relevante la importancia de la marca, dada la acogida que tiene en la zona la construcción de un Colegio Gredos San Diego desde el mismo momento de su anuncio.

Esta cada vez mayor dispersión de la actividad en diferentes centros hace necesario reforzar una gestión independiente de los colegios, en la búsqueda de que todos los centros tengan una entidad propia y no se conviertan en «sucursales» de Gredos San Diego Vallecas, y con la idea de reforzar la dimensión verdaderamente empresarial que supere ya definitivamente el concepto de Colegio y desarrolle el de Cooperativa, se implanta una Dirección General, que viene a profesionalizar la gestión, y se abre como Sede Social y oficina el pequeño edificio que fue el colegio Gredos San Diego originalmente.

\subsection{5-2011 (cuarta etapa): plan estratégico}

El traslado de la gestión al antiguo edificio supone no solamente un refuerzo de la organización de la empresa en su conjunto y la toma de una visión más global del proyecto educativo, esta ubicación favorece además que la Dirección General se visualice, incluso físicamente, como un equipo. 
En esta etapa, se produce un crecimiento impresionante que si bien supone un riesgo, no sólo económico, sino un verdadero reto en la capacidad de organización de la empresa, pone a prueba al equipo de la Cooperativa, y finalmente Gredos San Diego demuestra una fortaleza y una solidez que la sitúan en un nuevo camino.

El negocio se duplica en un espacio de tiempo asombrosamente corto con la apertura de tres nuevos centros, Las Rozas, Las Suertes y Guadarrama. La presencia de la cooperativa como referencia en la educación madrileña, y en el entorno del cooperativismo en España, da un vuelco a la visión que tiene de sí misma.

Comienzan a desarrollarse proyectos de gran relevancia interna, como la adaptación a las normas N.I.C., en la que es pionera en el sector; comienzan a implantarse políticas ya totalmente profesionalizadas, de calidad, marketing, sistema retributivo, evaluación por competencias, etc. y finalmente se produce un nuevo paso en la proyección de Gredos San Diego con la creación del Grupo Cooperativo GSD, que sitúa a la organización en un nuevo trabajo.

En este punto se encuentra la empresa en la actualidad, aunque no se abandonan los proyectos de crecimiento, sí que se busca un modelo de consolidación, de mejora continua en la organización, que posibilite no solamente la viabilidad económica y la excelencia productiva, sino que mantenga vivos los valores y principios cooperativos de solidaridad, democracia y búsqueda del bien común, que lejos de dificultar el desarrollo, en el caso de Gredos San Diego, se hacen visibles como una de las principales ventajas competitivas de la empresa.

Es el momento de consolidar la visión, por eso en 2011 se presenta para votación en la Asamblea de Socios, un nuevo plan estratégico, basado en cuatro tendencias, que sitúan a Gredos San Diego de cara al futuro, con una vocación de solidaridad y desarrollo del modelo cooperativo, de diversificación, de apuesta por las personas y el conocimiento, y de proyección internacional, que supone el reto más importante al que se ha enfrentado nunca la organización, pero que probará sin duda sus fortalezas y capacidades.

\section{A modo de resumen}

Este último texto ha sido extraído del libro «25 años forjando sueños» editado con motivo del 25 aniversario de Gredos San Diego y compuesto por D. Juan García, socio fundador de vital importancia en la trayectoria de la Cooperativa, en la que ha desarrollado una tareas 
de la más alta responsabilidad, desde director Gredos San Diego Vallecas, hasta presidente del Consejo Rector.

Viene resultando...

- Que la asamblea no es fin en sí misma, sino medio.

- Que nos hemos reunido en asamblea general en 43 ocasiones: una constituyente, veintidós ordinarias y veinte extraordinarias.

- Que la asistencia directa de socios ha superado holgadamente el $90 \%$.

- Que da duración media ha sido de tres horas y cuarenta minutos, en una banda de una a ocho horas.

- Que han sido siete los consejos rectores que nos han gobernado y tres los presidentes de los mismos.

- Que en diez ocasiones se han modificado los estatutos sociales y otras diez el Reglamento de Régimen Interno.

- Que la operatividad y el volumen de acuerdos ha sido inversamente proporcional al número de asistentes y a la duración de las asambleas: en las que la duración llegó a ocho horas, no se consiguió, prácticamente, acuerdo alguno; mientras resultó todo lo contrario en las que no sobrepasaron las dos horas.

- Que fuimos víctimas del asamblearismo inicialmente; hasta que conseguimos convertirla en el instrumento adecuado.

- Que sin las otrora asambleas largas, infinitas e inútiles tal vez no habrían sido posibles las posteriores útiles).

- Que el mayor número de asambleas por año se concentró en los diez primeros, y el menor, en los diez últimos.

- Que este recorrido, que más parecía camino de herradura hace veinticinco años, ha concluido en autopista.

- Que de la misma manera que somos visualizados desde el exterior magníficamente, debemos empeñarnos en serlo desde el interior.

- Que si cada año que pasa es más frecuente contemplar el crecimiento en la expansión de empresas que, como la nuestra, se dedican a la enseñanza, sólo se debe a una razón: la interpretación de la enseñanza como instrumento para transformar la sociedad -o conservarla- Francamente, debiera satisfacernos contar con tantas posibilidades en este empeño.

- Que debemos valorar justamente, con honestidad y legitimidad, cualquier medio que coadyuve nuestro fin último.

- Que nuestras Islas Caimán están, afortunadamente, en Congo, Kenia, Costa Rica y ACNUR, amén de en el empeño de seguir creando puestos de trabajo. 
- Que en tiempo en que se ha puesto de relieve la invalidez del sistema (aunque la manzana aun no esté madura del todo), nuestro modelo societario y empresarial debiera henchir nuestros pechos.

- Que ni el pasado ha muerto y ni está el mañana ni el ayer escrito. 